\title{
Occupation and scrotal cancer: Results of the NOCCA study
}

\author{
ROB H. A. VERHOEVEN ${ }^{1}$, LAMBERTUS A. L. M. KIEMENEY ${ }^{2,3}$, JAN WILLEM W. \\ COEBERGH $^{1,4}$, ELISABETE WEIDERPASS $^{5,6,7,8}$, KRISTINA KJAERHEIM ${ }^{6}$, JAN IVAR \\ MARTINSEN $^{6}$, ELSEBETH LYNGE $^{9} \&$ EERO PUKKALA $^{10,11}$ \\ ${ }^{1}$ Eindhoven Cancer Registry/Comprehensive Cancer Centre South, Eindhoven, The Netherlands, ${ }^{2}$ Department of \\ Epidemiology, Biostatistics and HTA, Radboud University Nijmegen Medical Centre, Nijmegen, The Netherlands, \\ ${ }^{3}$ Department of Urology, Radboud University Nijmegen Medical Centre, Nijmegen, The Netherlands, ${ }^{4}$ Department \\ of Public Health, Erasmus University Medical Centre Rotterdam, The Netherlands, ${ }^{5}$ Department of Medical Epidemiology \\ and Biostatistics, Karolinska Institutet, Stockholm, Sweden, ${ }^{6}$ Cancer Registry of Norway, Oslo, Norway, ${ }^{7}$ Samfundet \\ Folkhälsan, Helsinki, Finland, ${ }^{8}$ Department of Community Medicine, Tromso University, Tromso, Norway, ${ }^{9}$ University \\ of Copenhagen, Denmark, ${ }^{10}$ School of Public Health, University of Tampere, Tampere, Finland and ${ }^{11}$ Finnish Cancer \\ Registry, Institute for Statistical and Epidemiological Cancer Research, Helsinki, Finland
}

\section{To the Editor,}

Since the discovery of Percival Pott in 1775 that chimney sweeps had an increased risk of scrotal cancer, many occupations have been linked to an increased risk of cancer at this site [1,2]. With the hygienic improvement of the industrial working place in the 1960s and 1970s exposure to substances, such as tar and mineral oils, that may have caused these increased risks, have decreased substantially. It was expected that this would lead to a decrease of the incidence of scrotal cancer, but this does not seem to be the case in the USA and the Netherlands $[3,4]$.

Because the current risk factors for scrotal cancer are largely unknown, a nationwide population-based case-control study on the risks of scrotal cancer was conducted in the Netherlands. This study indicated that skin diseases or certain treatments for skin diseases might increase the risk of squamous cell carcinoma of the scrotum [5]. However, there were found no associations between exposure to any of the occupational substances and the risk of scrotal cancer, but the small size of the study (47 scrotal cancer cases) precluded firm conclusions.

To further study the association between occupations and scrotal cancer risk, we used the Nordic Occupational Cancer (NOCCA) cohort database, which holds accurate information on occupation and long-term follow-up for cancer for the populations of five Nordic countries (Denmark, Norway, Sweden, Finland and Iceland). The methods of the NOCCA project have been described in detail elsewhere [5]. Based on the observed and expected number of incident scrotal cancer cases, standardized incidence ratios (SIRs) were calculated for 53 occupational groups. We present here the SIRs for the occupational categories that have been previously reported in the literature as possibly associated with scrotal cancer (technical workers, textile workers, smelting workers, mechanics, chemical process workers, engine operators and chimney sweeps), as well as the occupational categories that we found to have significant or borderline significant (increased or decreased) SIR.

Altogether 328 scrotal cancers were diagnosed among the 7.4 million men (185 million personyears) who were followed up during the period 19612005 in the NOCCA cohort. Of all occupations with previous reports of elevated risks of scrotal cancer, only mechanics showed an overall increased risk $(\mathrm{SIR}=1.4,95 \%$ Confidence Interval (CI): 1.0-2.0) (Table Ia); this risk was only increased in the period 1961-1985 (SIR $=1.9,95 \%$ CI: 1.1-3.0), and not in the period 1986-2005 (SIR $=1.1,95 \%$ CI: 0.6-1.9). None of the chemical process workers or the chimney sweeps was diagnosed with scrotal cancer.

Correspondence: R. H. A. Verhoeven, Comprehensive Cancer Centre South (IKZ), Eindhoven Cancer Registry, PO Box 231, 5600 AE Eindhoven, The Netherlands. Tel: + 3140 2971616. Fax: + 3140 2971610. E-mail: research@ikz.nl 
Table I. Observed numbers of scrotum cancer among men in the Nordic countries and standardized incidence ratios, by occupational category and period.

Table Ia. Occupations that have been linked to scrotal cancer based on previous findings.

\begin{tabular}{|c|c|c|c|c|c|c|c|c|c|}
\hline \multirow{2}{*}{$\begin{array}{l}\text { Occupational } \\
\text { category }\end{array}$} & \multicolumn{3}{|c|}{ Total period } & \multicolumn{3}{|c|}{ Period 1961-1985 } & \multicolumn{3}{|c|}{ Period 1986-2005 } \\
\hline & Obs & SIR & $95 \% \mathrm{CI}$ & Obs & SIR & $95 \% \mathrm{CI}$ & Obs & SIR & $95 \% \mathrm{CI}$ \\
\hline $\begin{array}{l}\text { Technical } \\
\text { workers, etc }\end{array}$ & 23 & 1.1 & $0.7-1.6$ & 6 & 0.9 & $0.3-1.9$ & 17 & 1.2 & $0.7-2.0$ \\
\hline Textile workers & 2 & 0.6 & $0.1-2.3$ & {$[1.5]$} & 0.0 & $0.0-2.4$ & 2 & 1.3 & $0.2-4.5$ \\
\hline Smelting workers & 5 & 1.0 & $0.3-2.3$ & 4 & 1.7 & $0.5-4.3$ & 1 & 0.4 & $0.0-2.6$ \\
\hline Mechanics & 31 & 1.4 & $1.0-2.0$ & 16 & 1.9 & $1.1-3.0$ & 15 & 1.1 & $0.6-1.9$ \\
\hline $\begin{array}{l}\text { Chemical process } \\
\text { workers }\end{array}$ & {$[4.2]$} & 0.0 & $0.0-0.9$ & {$[2.1]$} & 0.0 & $0.0-1.8$ & {$[2.1]$} & 0.0 & $0.0-1.8$ \\
\hline Engine operators & 7 & 1.2 & $0.5-2.4$ & 2 & 0.9 & $0.1-3.1$ & 5 & 1.3 & $0.4-3.1$ \\
\hline Chimney sweeps & {$[0.2]$} & 0.0 & $0.0-18.2$ & {$[0.1]$} & 0.0 & $0.0-43.6$ & {$[0.1]$} & 0.0 & $0.0-31.1$ \\
\hline
\end{tabular}

Table Ib. Occupations with significant or near-significant standardized incidence ratios for scrotal cancer in the NOCCA-project.

\begin{tabular}{|c|c|c|c|c|c|c|c|c|c|}
\hline \multirow{2}{*}{$\begin{array}{l}\text { Occupational } \\
\text { category }\end{array}$} & \multicolumn{3}{|c|}{ Total period } & \multicolumn{3}{|c|}{ Period 1961-1985 } & \multicolumn{3}{|c|}{ Period 1986-2005 } \\
\hline & Obs & SIR & $95 \% \mathrm{CI}$ & Obs & SIR & $95 \% \mathrm{CI}$ & Obs & SIR & $95 \% \mathrm{CI}$ \\
\hline Sales agents & 22 & 1.6 & $1.0-2.5$ & 8 & 1.4 & $0.6-2.8$ & 14 & 1.8 & $1.0-3.0$ \\
\hline Wood workers & 11 & 0.6 & $0.3-1.1$ & 3 & 0.4 & $0.1-1.0$ & 8 & 0.8 & $0.4-1.6$ \\
\hline Launderers & 2 & 4.2 & $0.5-15.3$ & {$[0.2]$} & 0.0 & $0.0-16.8$ & 2 & 7.9 & $1.0-28.5$ \\
\hline
\end{tabular}

CI, confidence interval; Obs, observed number of cases; SIR, standardized incidence ratio.

In cells where the observed number of cases is zero, the expected number cancer cases are presented in square brackets.

Significant or borderline significant SIRs were further found among sales agents $(\mathrm{SIR}=1.6,95 \%$ CI: $1.0-2.5)$ and wood workers (SIR $=0.6,95 \% \mathrm{CI}$ : 0.3-1.1) during the entire study period (Table Ib) and for launderers for the period 1986-2005 $(\mathrm{SIR}=7.9,95 \%$ CI: $1.0-28.5)$. There were no launderers diagnosed with scrotal cancer in the first period, resulting in a SIR for the entire study period of 4.2 (95\% CI: $0.5-15.3$ ).

Thus, from the occupational categories that have been previously reported as associated with scrotal cancer, only mechanics (including metal workers) were found to have an increased risk in this study, and only in the first period (1961-1985). Taking into account the latency period between exposures to carcinogenic substances and the development of scrotal cancer, as well as the substantial improvements in the working environment hygiene conditions during the first part of the observation period of this study, an increased risk for a traditional risk occupation for scrotal cancer, if any, would likely be detected in the first time period of our study (1961-1985).

We did not find any other increased risk of scrotal cancer among men in occupations previously reported to be associated with an increased risk of scrotal cancer. This may indicate that there no longer is an association with occupations or that the exposure to scrotal cancer carcinogens has decreased to such a low level that there no longer is an increased risk. However, since most previous most observations on the possible risk factors of scrotal cancer have been made in the UK and the USA, it is also possible that there never has been an increased risk for these occupations in the Nordic countries.

The increased risk among launderers in the last study period and the increased risk among sales agents over the whole study period can not be explained easily. Consistence of results between countries and the existence of biological plausibility might indicate that increases in SIRs are causally related to occupational exposures. Because there were only two launderers diagnosed with scrotal cancer (both Swedish), it is impossible to look at consistency among the countries for this occupational group, which in turn makes it impossible to make any strong conclusions on the causal association between launderers and scrotal cancer. The increase in SIR among sales agents was consistent in each of the Nordic countries for the entire study period. However, sales agents are not expected to have any occupational exposure to carcinogenic substances, such as soot, tar and oil, and therefore there is little biological plausibility for an occupationally increased risk of scrotal cancer. A previous report from the NOCCA-cohort showed that male sales agents have increased SIRs for melanoma and non-melanoma skin cancer [6]. As almost all of the scrotal cancers are skin cancers, the same risk factors as for melanoma and non-melanoma 
1246 R. H. A. Verhoeven et al.

skin cancers (sun exposure and sun burns) could in theory explain the association. However, the scrotal region is usually protected from the sunshine by clothing and an increased risk of scrotal cancer by ultraviolet (UV) radiation therefore seems unlikely. The SIRs for wood workers were consistently below unity in all Nordic countries, but we are unaware of any plausible biological mechanism that may explain this finding. Finally, we cannot rule out the possibility that these are chance findings. For this study SIRs have been presented for 53 occupational categories and two different time periods. Inevitably, a number of these combinations may by chance have had significantly decreased or increased SIRs.

In conclusion, this study suggests that scrotal cancer is not related to occupational risk factors in the Nordic countries during at least the last two decades.

\section{Acknowledgements}

We thank Laufey Tryggvadóttir from the Icelandic Cancer Registry, Hólmfríður Gunnarsdóttir from the Faculty of Medicine, University of Iceland and Pär Sparén from the Department of Epidemiology and Biostatistics of the Karolinska Institute in Stockholm for their contributions to the NOCCA project and their contributions to this letter.

Declaration of interest: The authors report no conflicts of interest. The authors alone are responsible for the content and writing of the paper.

\section{References}

[1] Lowe FC. Squamous-cell carcinoma of the scrotum. Urol Clin North Am 1992;19:397-405.

[2] Waldron HA. A brief history of scrotal cancer. Br J Ind Med 1983;40:390-401.

- [3] Verhoeven RH, Louwman WJ, Koldewijn EL, Demeyere TB, Coebergh JW. Scrotal cancer: Incidence, survival and second primary tumours in the Netherlands since 1989. Br J Cancer 2010;103:1462-6.

- [4] Wright JL, Morgan TM, Lin DW. Primary scrotal cancer: Disease characteristics and increasing incidence. Urology 2008;72:1139-43.

[5] Verhoeven RHA, Aben KKH, Reedijk AM, Botterweck AA, Veerbeek L, Visser O, van der Aa MA, Ho CKY, Coebergh JWW, Kiemeney LALM. Etiology of scrotal cancer, a nationwide case-control study in the Netherlands. Submitted.

- [6] Pukkala E, Martinsen JI, Lynge E, Gunnarsdottir HK, Sparen P, Tryggvadottir L, Weiderpass E, Kjaerheim K. Occupation and cancer - follow-up of 15 million people in five Nordic countries. Acta Oncol 2009;48:646-790. 